In the absence of

any geographical

sourcing

appendix, the

European nations

are still applying

their existing

national rules to

serum

importation.

\section{Trust or Treatment?}

So what is wrong with draft 7 (apart from the bureaucratic burden that having to compile and distribute seven drafts obviously entails)? The first problem area is the appendix that designates from which third party countries (outside the EU) serum may and may not be imported without treatment or further testing. Currently, there is no such list of acceptable sources. Compiling it would clearly involve knowing the disease status for a range of conditions in a given country-a relatively straightforward demand-but one that is complicated by the question of mutual trust and recognition between veterinary authorities.

The veterinary authorities might not phrase it so simplistically, but, in effect, at some point they have to decide whose declarations of disease-free status they can afford to believe. At one level, there are the World Health Organization (WHO, Geneva, Switzerland) and other internationally accepted designations of disease status on a nation-by-nation basis. But there are also "gray areas" where a disease is apparently confined to regions of a country. Australians, for instance, tell me that blue tongue virus is confined to Victoria; non-Australians consider that only New South Wales and the island of Tasmania are blue tongue-free (see "Cleaning Up in the Antipodes"). Where decisions are based on opinion and interpretation, rather than data, the path to agreement is likely to be long and stony.

In the absence of any geographical sourcing appendix, the European nations are still applying their exist- ing national rules to serum importation. This is quite legitimate, but nevertheless perpetuates confusion in the mind of the serum consumer and obstructs clarity.

According to Life Technologies' Miller, another problem with the current draft of the technical annex to Directive $92 / 118$ is the provision-designed to circumvent the sourcing question-that would allow the importation of serum from South America as long as it had been treated to remove any viral risk to animal health in Europe. The primary concerns of the veterinary authorities is to prevent the importation of diseased material that might cause a problem for domestic agriculture. The target diseases are foot-and-mouth and blue tongue. The treatments that have been deemed appropriate are heating for 3 hours at $65^{\circ} \mathrm{C}$, gammairradiation at 2.5 megarad, or lowering $\mathrm{pH}$ to 5 for 3 hours. All these treatments can reduce virus titers by a factor of $10^{6}$. However, the treatments also reduce the efficacy of serum in its primary role for biopharmaceutical R\&D, that of promoting the growth of mammalian cell lines. Imposition of these rules, according to Miller, ". . . may well mean that these sources are unavailable for the (cell culture) market." Given that South American serum costs around \$75 per liter, compared to over $\$ 300$ per liter for New ZealandAustralian-U.S.-and USDA-approved sources, that might mean that many academic serum users are priced out of cell culture altogether (see "Viable Alternatives to Fetal Bovine Serum).

\title{
Viable Alternatives to Fetal Bovine Serum
}

The near cartel-like situation in the fetal bovine serum (FBS) market has led to a search for serum equivalents that would theoretically be free of the myriad problems associated with it. Serum equivalent promoters, such as Dr. Richard Ham, scientific advisor to Clonetics (San Diego, CA), believe there is a gradual but steady trend toward the use of equivalents. "In many cases, serum is undesirable, especially with the presence of biocontaminants, and with the problems that occur when separating the desired product from the serum." Moreover, certain cell types that are now being used with great frequency, such as human epithelial cells, are best cultured with serum equivalents.

This trend seems to be confirmed by the fact that many serum supply companies have both serum and serum equivalent lines, and many companies state that they believe the future lies in serum equivalents. The serum equivalent world has been spurred on by the increasing availability of recombinant growth factors for use in equivalents. Clonetics, with its specific human cell lines and accompanying serum equivalents is one example of developments in this area.

Serum equivalent detractors, of which there are few, state that the disadvantages of serum equivalents - such as their delicacy, inability to sustain vigorous cell growth, and the absence of a universal serum equivalent that can be used in various different cell lines-are serious stumbling blocks. This could delay their widespread use and ultimately limit them to sharing a significant portion of the market with sera such as FBS.

Nonetheless, Richard Ham believes serum equivalents will first enter monoclonal antibodies and low-maintenance cell lines such as Chinese hamster ovary ( $\mathrm{CHO}$ ) lines, a prediction borne out by the work of Michael Zang, Jakob
Reiser, and their colleagues at the Swiss Federal Institute of Technology (Zurich) and CibaGeigy (Basel, Switzerland), as reported in the research pages of this issue.

With the increasing demand for serum equivalents in the biotech industry, there is a potential for crisis, says Ham. Grants for basic research in serum equivalents are not on the National Institutes of Health (Bethesda, MD) priority list. This leads many to believe that the industry would be better served by pooling its resources in developing serum-free media, rather than independently reinventing the proprietary wheel, as is currently the case. Serum equivalents will play a much larger role in the future, but with basic research into sera equivalents-a traditional supplier of the intellect behind innovationfaltering, FBS will not face a serious challenge in the near future. 